Materials for cleaning buildings have been under review, and a number of proprietary preparations investigated. It is pointed out that it is inadvisable to use chemical methods, and that alkalis are equally as dangerous as acids. Examples of the deleterious effects of cleaning in stone walls, door jambs, etc., are quoted.

Work on the effect of firing conditions on the properties of bricks has shown that specimens fired to below $900^{\circ} \mathrm{C}$. offered only a moderate resistance to disruption by the crystallization of soluble salts whereas, with one exception, all the clays tested proved satisfactory in this respect when fired to $1,000^{\circ} \mathrm{C}$. The unsightly efflorescence on brickwork is caused by soluble magnesium compounds, particularly the sulphate, contained in the bricks, and the only certain method of its elimination is firing to a temperature of above $1,050^{\circ} \mathrm{C}$.

The report also contains particulars of tests made on the heating, cooling and lighting of buildings. The notable difference in the temperatures inside a wooden shed, before and after whitening it, is shown in the results of one inquiry, while the diminution of the lighting of a room due to a balcony or neighbouring building is the subject of another. Particulars of the work carried out in conjunction with other bodies and on behalf of manufacturers, indicate the value of the scientific services rendered by the Building Research Board both to the industry and to the interests of the public.

\title{
The Machinery of the Queen Mary
}

\begin{abstract}
7 HE ninth Thomas Lowe Gray lecture was delivered before the Institution of Mechanical Engineers on January 8 by Mr. John Austin, super. intendent engineer, Cunard White Star, Ltd., and took the form of a description of the main and auxiliary machinery of the Queen Mary.

Mr. Austin pointed out that since the advent of steam propulsion, the trend of development in the design of Atlantic liners has been towards larger and faster ships, and the several commercial and technical considerations which determined the size and speed of the new vessel were explained. Before a decision was taken as to the type of machinery to be installed, a committee of eminent engineers was invited to advise the directors, and they unanimously recommended high-pressure water-tube boilers with superheaters and air-preheaters and, for propulsion, single reduction geared turbines as being most suitable by reason of their reliability, simplicity, lightness, efficiency and freedom from noise and vibration. To meet emergencies and to maintain the fortnightly schedule, a large reserve of steaming capacity was provided and, in relation to the normal power required, it is of particular interest to the engineer to note how much design of hull and propellers has improved. From the table of figures given, the Lucania of 1893 had a gross tonnage of 12,952 , horse-power 27,650 and speed $21.9 \mathrm{knots}$. The Queen Mary has 6.2 times the tonnage, but only $5 \cdot 7$ times the horse-power, although her speed is $1 \cdot 2$ times that of the Lucania.
\end{abstract}

The arrangements to ensure economy and to obviate delays and damage are as complete as human ingenuity can make them. Salt-water detectors are fitted at every point where salt-water might leak into the feed-water system, and give audible and visible warning when the concentration reaches 2 grains per gallon. Automatic feed-water regulators ensure a steady water-level in the boilers. The adoption of the closed stokehold system of forced draught has obviated the need for massive air ducts, and maintains better ventilation and working conditions. Fach boiler has a complete system of steam soot blowers, and the arrangement by which boilers and propelling machinery have been divided into two quite independent systems-only practicable in a ship of such large size and power-ensures that, in the event of breakdown in one section, the whole propelling machinery is not put out of action.

The steering and mancuvring of a ship of this size necessitates a rudder of large area and, this being of streamline unbalanced type, powerful operating gear had to be installed. The torque is supplied by four hydraulic rams acting on tillers projecting from the rudder-stock. For safety, the essential parts were duplicated and the pumps are driven by three electric motors each of 250 h.p., the switchboard of which is operated by servo gear of the electro-hydraulic type controlled by hydraulic telemotors working in conjunction with the steering wheel on the bridge.

\section{Crystalline Structure of Cellulose}

$\mathrm{P}$ ROF. K. H. MEYER reviews in the February issue of the Berichte der deutschen chemischen Gesellschaft the evidence upon which the structure of the crystalline part of cellulose has been based, and suggests that certain alterations are needed in the accepted model which was constructed from $\mathrm{X}$-ray intensity measurements carried out by Andress in 1929 .

Fortunately, the existing calculations upon the dimensions of the micelles or crystallites remain for the most part undisturbed, since the latter are independent units and the cellubiose type of linkage is not challenged. But the grouping of the micelles needs reconsideration. Hitherto it has been assumed that they all run in the same direction.

There seems to be no valid proof that this is the case, and the fact that precipitated hydratcellulose possesses the same crystal lattice as that of the mercerized fibre makes it highly improbable that all the chains are similarly orientated. There is, in fact, no reason why an equal number of chains should not be formed in opposite directions by precipitation. 